\title{
The effect of oxygenation by continuous low- pressure oxygen flow through thyrocricocentesis cannulation on asphyxia-induced injury in canines: a randomized prospective animal study.
}

\section{Fengyi Huang}

Fujian Provincial Hospital

\section{Feng Chen}

Fujian Provincial Hospital

Xiaochun Zheng ( $\nabla$ zhengxiaochun7766@163.com)

Fujian Provincial Hospital https://orcid.org/0000-0002-6213-0789

\section{Fei Gao}

Fujian Provincial Hospital

\section{Research article}

Keywords: continuous low-pressure oxygen; venous catheter needle; thyrocricocentesis; continuous oxygenation; partial pressure of oxygen; brain; heart; prognosis

Posted Date: August 3rd, 2019

DOI: https://doi.org/10.21203/rs.2.12383/v1

License: (9) This work is licensed under a Creative Commons Attribution 4.0 International License. Read Full License 


\section{Abstract}

Background To observe the oxygenation efficacy using a continuous low-pressure oxygen flow through thyrocricoid emergency airway by venous catheter needle in asphyxic canine models. Methods Eighteen healthy male canines were randomly assigned to three groups: group A (control), group B (continuous low-pressure oxygen flow insufflation), and group $C$ (continuous low-pressure oxygen flow insufflation with chest compression). After thyrocricocentesis cannulation and intubation, ventilation was stopped for 40 minutes to establish an asphyxic model. Electrocardiogram, arterial blood pressure, oxygen saturation, heart rate, and arterial blood gas analysis were performed in that duration. Concentrations of $\mathrm{S} 100 \beta$ protein, cardiac troponin I, and creatine kinase isoenzyme and moisture ratio of brain tissue were measured before asphyxia and 2 hours and 4 hours after resuscitation. Measurement data was described as mean $\pm S D$; one-way analysis of variance (ANOVA) or paired t-test was used to determine differences over time within groups. A p-value $<0.05$ was considered statistically significant. Results The pace of decline in oxygen saturation, partial pressure of oxygen, and $\mathrm{pH}$ and rise in partial pressure of carbon dioxide and lactate were slower in the other two groups than in the control group. Similarly, a delay in the increase in concentration of $\mathrm{S} 100 \beta$ protein and cardiac troponin I was observed. Moreover, cerebral edema in groups $B$ and $C$ was significantly alleviated. The level of serum $S 100 \beta, c T n l$, and moisture ratio of brain tissue was lower in group $C$ than in group $B(p<0.05)$. Conclusions The implications of continuous low-pressure oxygen flow insufflation through venous catheter needle after thyrocricoid puncture with assisted chest compression can ameliorate oxygenation in vivo, slow the increase of partial pressure of carbon dioxide, and reduce the accumulation of $\mathrm{H}+$ ions. Consequently, it could attenuate the injury to vital organs, and hence improve prognosis. The study showed that it can be a promising approach for managing patients with asphyxia in routine clinical settings.

\section{Introduction}

In the practice of clinical anesthesia, first aid, and resuscitation, failure of exposure by laryngoscope and failure or difficulty in mask ventilation are referred to as "difficult airway." It is a critical situation that clinicians may encounter in routine surgical cases. Difficult airway is often encountered in emergency situations, and improper treatment can lead to asphyxia or even cardiac arrest, in few minutes (1). It is reported that the incidence of difficult airway may range from $1 \%$ to $4 \%$ during the administration of anesthesia (2). Due to the comparatively low incidence rate of difficult airway, most anesthesiologists may not have enough experience in managing this critical situation.

At present, the best means to manage a difficult airway is fiberoptic bronchoscope. However, because of its high price, it may be difficult to popularize its use, especially in primary hospital settings. During management of the unpredictable difficult airway, time is the most important factor. However, tracheal and cricothyroid membrane incision can often waste a lot of time, even by specialized medical personnel using special surgical instruments. Thyrocricocentesis requires a short period of time to set up an emergency airway, and hence it plays an important role in emergency cases (3). 
However, it is difficult to decide the next step for providing adequate ventilation after successful thyrocricocentesis. The aim of the present study was to find an effective mode of ventilation with the most simple, safe, and efficient approach in this emergency situation. In this study, we ceased the ventilation in canines to simulate an asphyxic model and evaluated the efficacy of oxygenation using continuous low-pressure oxygen flow through thyrocricoid emergency airway with venous catheter needle. Meanwhile, we observed and analyzed the changes caused by hypercapnia in vital organs, such as heart and brain.

\section{Materials And Methods}

This prospective, randomized, laboratory study was conducted with the ethical approval of Fujian Medical University Institutional Animal Care Committee and the Fujian Provincial Hospital Animal Care and Use Committee. All animals received treatments in compliance with the National Research Council's 1996 Guide for the Care and Use of Laboratory Animals.

\section{Animal preparation}

The study was performed on 18 healthy adult male canines weighing 10 to $15 \mathrm{~kg}$. All animals were provided by Animal Center of Fujian Medical University. Before the operation, all animals fasted for 12 hours, and fluids were withheld for 4 hours (4). Animals were kept in a clean environment at suitable temperature and humidity. They were randomized into three groups in a blinded manner with a sealed envelope indicating their assignment to groups. Group A (control group, $n=6$ ), group B (continuous lowpressure oxygen flow insufflations (LPOFI) after 40-minute asphyxia, $n=6$ ), group $C$ (continuous lowpressure oxygen flow insufflations accompanied by chest compression (LPOFI-CP) after 40-minute asphyxia, $n=6$ ). Operation was performed as previously described (5). The anesthesia protocol was as follows:

Sedation: intramuscular injection of ketamine $10 \mathrm{mg} / \mathrm{kg}$.

Induction: propofol $1.0 \mathrm{mg} / \mathrm{kg}$, sufentanil $0.4 \mu \mathrm{g} / \mathrm{kg}$, and cisatracurium $0.3 \mathrm{mg} / \mathrm{kg}$ were injected through the ear vein as per our previous experiment.

Fixing: supine, fixed the limb, and the tongue was protracted to prevent suffocation. Monitoring: arterial pressure was measured at femoral artery puncture (normal values: $180 \pm 20 / 136 \pm 15 \mathrm{~mm} \mathrm{Hg}$ ), electrocardiography (ECG) (HR: $125 \pm 20$ beats per minute), respiration ( $23 \pm 5$ breaths per minute), oxygen saturation $\left(\mathrm{SpO}_{2}\right.$; clamp the probe to the tongue), airway pressure.

Intubation: The anesthetized animals were intubated, and a ventilator with volume-controlled mode was utilized to maintain fractional inspired oxygen $\left(\mathrm{FiO}_{2}\right)$ level of 1.0. 
Maintenance: Continuous infusion of propofol (1.0 mg/kg per hour), sufentanil ( $0.4 \mu \mathrm{g} / \mathrm{kg}$ per hour), and cisatracurium ( $0.3 \mathrm{mg} / \mathrm{kg}$ per hour) was continued.

Thyrocricocentesis: a venous catheter needle was used, stylet was withdrawn, and the catheter was immobilized. Accurate placement of the catheter was confirmed by the airflow through the catheter.

Euthanasia: After completion of the medical study, animals were euthanized by injection of potassium chloride in deep anesthesia with propofol.

\section{Experimental protocol}

After intubation, the animals were allowed to equilibrate for 30 minutes to achieve a stable level (the range of systolic blood pressure was $120 \pm 20 \mathrm{mmHg}$ and the heart rate was $130 \pm 20$ beats per minute), and baseline data was collected. In the control group, hypoxia was induced by extubation and stopping ventilation without any rescue measures; in group B, 40-minute hypoxia was followed by continuous 5 $\mathrm{L} / \mathrm{min}$ fresh oxygen insufflation through thyrocricocentesis cannulation with airway pressure lower than $35 \mathrm{cmH}_{2} \mathrm{O}$, after which intubation and ventilation were continued; in group C, 40-minute hypoxia was followed by insufflations accompanied by chest compression (20 times per minute).

\section{Measurement}

\section{Arterial blood gas analysis}

Arterial blood samples for gas analysis including $\mathrm{SpO}_{2}$, partial pressure of oxygen $\left(\mathrm{PaO}_{2}\right)$, partial pressure of carbon dioxide $\left(\mathrm{PaCO}_{2}\right), \mathrm{pH}$, and lactic acid ( $\left.\mathrm{LAC}\right)$ were drawn prior to experiments for baseline control and at 5, 10, 15, 20, 25, 30, 35, and 40 minutes after hypoxia. Arterial blood gas analysis was performed by using automatic blood gas analyzer (GEM PREMIER 3500).

\section{S100 $\beta$ protein, $c T n l$, and creatine kinase isoenzyme (CK-MB) measurement}

Blood samples for $\mathrm{S} 100 \beta$ protein, $\mathrm{CTnl}$, and CK-MB measurement were drawn prior to hypoxia and 2 and 4 hours after ventilation resumption. $S 100 \beta$ protein was measured by using enzyme-linked immunosorbent assay (ELISA), and chemiluminescent immunoassay was utilized for measuring cTnl, CK-MB by using automatic chemiluminescence immunoassay analyzer (ADVIA Centaur CP, SIEMENS).

\section{Determination of moisture ratio of brain tissue}


After the animals were sacrificed 4 hours after intubation in group B and C, several pieces of brain tissues of $1 \mathrm{~mm}^{3}$ each, were excised from the two halves of parietal cortex. Moisture ratio of brain tissues was determined by dry-wet weight method. The wet weight of gross specimens from both hemispheres, dried on filter paper, was measured by precision electronic balance. The specimens were placed in a drying oven at $110^{\circ} \mathrm{C}$ for 24 hours, and the dry weight was measured. The difference between the two measurements was less than $0.5 \mathrm{~g}$.

Calculated as follows: (6)

[Due to technical limitations, this equation is only available as a download in the supplemental files section.]

\section{Statistical analyses}

Statistical analyses were performed using SPSS 11.5 software. Measurement data was described as mean $\pm S D$; one-way analysis of variance (ANOVA) or paired $t$-test was used to determine differences over time within groups. A $p$-value $<0.05$ was considered statistically significant.

\section{Results}

\section{Comparisons of blood gases and lactate}

Canines in the control group were dead about 15 minutes after hypoxia. Correspondingly, $\mathrm{SpO}_{2}$ was too low to be measured at 5 minutes after hypoxia in this group. The $\mathrm{SpO}_{2}$ in group $\mathrm{B}$ and $\mathrm{C}$ decreased over time. However, $\mathrm{SpO}_{2}$ in group $\mathrm{B}$ was lower at varying time points from 30 to 40 minutes after hypoxia than that in group $\mathrm{C}(p<0.05)$.. (Fig. 1A)

The $\mathrm{PaO}_{2}$ decreased to $5.36 \pm 2.10 \mathrm{mmHg}$. By contrast, in both group $\mathrm{B}$ and group $\mathrm{C}$, fresh oxygen insufflation maintained the $\mathrm{PaO}_{2}$ effectively after hypoxia. In group $\mathrm{B}, \mathrm{LPOFI}$ raised $\mathrm{PaO}_{2}$ continuously in a time-dependent manner, and similarly, $\mathrm{PaO}_{2}$ increased slightly after hypoxia and was maintained at normal range in group $\mathrm{C}$. However, difference between the two groups was statistically significant $(p<$ 0.05).. (Fig. 1B)

$\mathrm{PaCO}_{2}$ in all three groups increased at varying time points. However, $\mathrm{PaCO}_{2}$ in group $\mathrm{C}$ was significantly lower at varying time points than that in group B $(p<0.05)$.. (Fig. 1C)

In all three groups, $\mathrm{pH}$ value decreased in a time-dependent manner. However, $\mathrm{pH}$ value declined mildly in both group $B$ and $C$ than that in control group $(p<0.05)$.. (Fig. 1D)

LAC increased sharply after hypoxia in group A, was $3.89 \mathrm{mM}$ at 15 minutes after hypoxia. On the contrary, the level of blood LAC was slightly elevated 10 to 20 minutes after hypoxia in groups $B$ and $C$ ( $p$ 


\section{Comparisons of serum S100 $\beta$ protein, cTnl and CK- MB}

Since canines in the control group were dead about 15 minutes after ventilation was stopped, the values of serum S100 $\beta$ protein, $\mathrm{cTnl}$ and CK-MB in this group were not measured. Serum S100 $\beta$ protein and cTnI values increased significantly in a time-dependent manner in both group $B$ and $C$. The values of serum $S 100 \beta$ and $c T n I$ were significantly lower in group $C$ than in group B, 2 and 4 hours after ventilation resumption $(p<0.05)$,, suggesting that continuous low-pressure oxygen insufflation with combined chest compression has superior therapeutic effects. The CK-MB values remained stable, and no statistically significant difference was observed $(p>0.05)$.. (Fig. 2A-C)

\section{Moisture ratio measurement of brain tissue}

Three canines were randomly selected to be sacrificed for measurement of moisture ratio of parietal cortex tissue, which was taken as control. Moisture ratio in brain tissues was significantly raised after hypoxia in both group $\mathrm{B}$ and group $\mathrm{C}(p<0.05)$, however, moisture ratio at same time point was significantly higher in group B than that in group $C(p<0.05)$ ", suggesting that continuous low-pressure oxygen insufflation with combined chest compression has superior therapeutic effects. (Fig. 3) The report on histology of brain edema in each group is shown in Fig. 4(A-F).

\section{Discussion}

In the present study it was proved that the use of continuous low-pressure oxygen insufflation through venous catheter needle after thyrocricoid puncture with assisted chest compression can ameliorate oxygenation in vivo. Moreover, it could inhibit the increase of $\mathrm{PaCO}_{2}$ and reduce the accumulation of $\mathrm{H}^{+}$ ions in blood, i.e., reduction of blood $\mathrm{pH}$. It is crucial that the heart and brain should be protected from the ill-effects of asphyxia, which can eventually lead to an improved prognosis. The findings from the present study suggest a simple, safe, and effective method of managing patients with asphyxia in routine clinical and surgical settings.

The prevention of the "difficult airway," which has a potential risk of being converted into "emergency airway," can be closely related to the safety and quality of anesthesia. With more than $30 \%$ of serious complications, the major cause of anesthesia-related morbidity and mortality can be attributed to improper airway management, which can convert "difficult airway" to "emergency airway" and may results in hypoxia and asphyxia (7). Emergency airway can occur as anesthesia induction, maintenance, extubation, recovery, and postoperative stages can differ with a variety of influential factors. Readily 
accessible emergency airway facilities, which maintain adequate oxygenation during emergency airway situations, are therefore essential until definitive procedures for establishing an effective artificial airway can be instituted.

As a minimally invasive and effective technique, performing thyrocricocentesis and inserting the venous needle catheter can re-establish a temporary airway in a short time, usually within 60 seconds (8). However, whether fresh oxygen insufflation through thyrocricocentesis cannulation can provide sufficient oxygen supplement and avoid asphyxia, is still unclear. Therefore, we investigated the impact of oxygen insufflation through thyrocricocentesis cannulation on blood gases, $\mathrm{pH}$, and $\mathrm{LAC}$ of canines without effective ventilation. We further measured serum $S 100 \beta$ protein, $C T n I, C K-M B$, and moisture ratio of brain tissue to demonstrate whether oxygen insufflation can prevent or reduce damage from asphyxia in canines.

Since oxygen exchange in alveolus follows the concentration diffusion theory, the alveolar-arterial oxygen difference is the primary factor that determines direction of oxygen exchange. However, the amount of oxygen exchange is mostly influenced by the areas of oxygen exchange. Alveolus, the units for pulmonary gas exchange, have a total area of nearly $130 \mathrm{~m}^{2}$ (9). In this study, we provided positive airway pressure by using fresh oxygen insufflation through thyrocricocentesis cannulation, which prevented alveolus collapse. Additionally, the pressure gradient improved the oxygen absorption in diffusion areas, promoted oxygen exchange to enhance oxygen content in serum, which increased the oxygen reserve and helped in alleviating the hypoxia status. In this study, hypoxic canines that received continuous low-pressure oxygen insufflation survived for more than 40 minutes, demonstrating that, for urgent cases oxygen insufflation through thyrocricocentesis cannulation can be helpful until definitive procedures for achieving adequate ventilation can be instituted.

However, if effective ventilation is not achieved, such an approach will result in carbon dioxide accumulation. It is believed that chest compression can reduce $\mathrm{CO}_{2}$ accumulation by thoracic movement and subsequent passive pulmonary ventilation. Therefore, continuous oxygen insufflation with combined chest compression was performed to investigate whether this method can provide sufficient oxygenation and reduce carbon dioxide accumulation. Various physiological parameters of canines including $\mathrm{SpO}_{2}$, $\mathrm{PaO}_{2}, \mathrm{PaCO}_{2}, \mathrm{pH}$ value, and serum LAC were measured. In our study, we found that oxygen insufflation with or without chest compression can increase the $\mathrm{PaO}_{2}$ in circulation. Furthermore, it was shown that continuous low-pressure oxygen insufflation was more effective in improving the $\mathrm{PaO}_{2}$, while oxygen insufflation combined with chest compression was more likely to keep $\mathrm{PaO}_{2}$ in the normal range. The two methods can hamper the increase of $\mathrm{PaCO}_{2}$ and the disturbance of acid-base balance, out of which, the efficiency of chest compression was particularly evident.

Hypoxia can cause injury to vital organs, specially heart and brain. In our study, we further measured S100 $\beta$ protein, CTnl, CK-MB, and moisture ratio in brain tissue of subjects who were treated with these two methods to investigate the influence of the two treatments in these organs. 
As one of the acid calcium binding protein, serum $\mathrm{S} 100 \beta$ protein has a small molecular weight, and its concentration is not affected by age, hemorrhage, temperature, or heparin. The $\beta$ subunit of $S 100 \beta$ is highly specific for central nervous system (CNS) and is a specific biochemical marker of brain injury (10). Normally, $\mathrm{S} 100 \beta$ protein cannot pass the blood-brain-barrier (BBB) unless the brain tissue is damaged (11). In such cases, $S 100 \beta$ protein in cerebrospinal fluid can easily pass the BBB and is detected in blood, the concentration of which has a positive correlation with the severity of injury in CNS (12). ChaparroHuerta et.al (13) demonstrated that in neonates with asphyxia, the concentration of serum S100 $\beta$ protein can reflect the severity of brain injury, can be a predictor of its progression, and is closely related to the condition and prognosis of brain injury secondary to hypoxia and ischemia of brain. In this study, serum $S 100 \beta$ protein of hypoxic canines in group $B$ and group $C$ was relatively high compared with the control group, which suggested that hypoxia and hypercapnia can cause damage to the BBB. However, in similar hypoxic conditions, the level of serum $S 100 \beta$ protein of group $C$ was lower than that of group $B$, which indicated that supplemental chest compression can further relieve hypercapnia-induced brain damage.

Brain edema can, to some extent, reflect the severity of hypoxia. The principal parameter to evaluate brain edema is the moisture ratio in brain tissue (14). Hypoxia may lead to dysfunction of cerebral autoregulation, which once exceeds the tolerable limit, can cause brain edema, intracranial hypertension, and even cerebral hemorrhage (15). According to the results, hypoxia can apparently worsen the moisture ratio of brain tissue in the control group. In Group B and Group C, with the same duration of resuscitation after hypoxia, moisture ratio of brain tissue was significantly higher in Group B than that of the Group C, which suggested that continuous low-pressure oxygen insufflation combined with chest compression exhibit remarkable therapeutic effects. Besides, as shown by Group C, moisture ratio of brain tissue shows no significant increase compared with the results of 2 hours or 4 hours after resuscitation, while in some cases, the values might even decrease. This indicates that supplemental chest compression can, to a great extent, alleviate hypercapnia induced brain damage, or even reverse the brain damage secondary to hypoxia, thus improving the prognosis of patients with hypoxia, and serving to provide a valuable option for managing a patient with hypoxia in the emergency department.

Cardiac troponin I (cTnl), one of the components of the cardiac troponin complex, is expressed only in myocardium; its values do not change even in cases of skeletal muscle injury (16). Normally, it cannot penetrate the cell membrane of cardiac muscle, and hence is hardly detected in plasma. When myocardial hypoxia and ischemia occur, followed by secondary degeneration and necrosis, the highly specific biochemical marker of myocardial cTnl, can enter the interstitial tissue, and is detected at early stages in circulation. Serum concentration of cTnl above $5 \mathrm{~g} / \mathrm{L}$ can be regarded as myocardial lesion (17). Our study revealed that, compared with the control group, serum level of cTnI was significantly elevated in Group B and Group C. Moreover, under the same hypoxic duration, serum level of cTnI was higher in group $B$ than in group $C$, which indicates that, supplemental chest compression can alleviate myocardial damage due to hypoxia and improve the tolerance limit of survival of myocardium to hypercapnia. As for CK-MB, another biomarker for myocardial injury, is released into circulation 6 hours after myocardial injury (18). However, since its fluctuation occurred after the end of our observation 
period, except for a significant increase of serum CK-MB in few subjects, in most subjects, the anticipated result could not be obtained.

Several limitations need to be considered when interpreting our findings. First, as this was an animal experiment, the data and results can only serve as a clinical reference. Second, experiments were restricted by the sample size and lack of repeat tests, and hence the obtained results are correspondingly short of conviction. Third, the kidneys, like heart and brain, are also highly sensitive to acute hypoxia, and further investigations will be required to investigate kidney damage in such conditions.

Taking into account the above mentioned factors, it can be suggested that thyrocricocentesis cannulation can rapidly establish a temporary airway for ventilation, prevent the symptoms of hypoxia, and attenuate the subsequent injury of vital organs.

\section{Conclusions}

Fresh oxygen insufflation through thyrocricocentesis cannulation accompanied by chest compression can be an appropriate choice for severe acute upper respiratory tract obstruction, which is difficult to manage by emergency tracheal intubation or tracheotomy.

\section{List Of Abbreviations}

ECG electrocardiogram

ABP arterial blood pressure

$\mathrm{SpO}_{2}$ oxygen saturation

HR heart rate

LAC lactic acid

cTnl cardiac troponin I

CK-MB creatine kinase isoenzyme

ELISA enzyme-linked immuno sorbent assay

CLIA chemiluminescent immunoassay

ANOVA one-way analysis of variance

\section{Declarations}


Ethics approval and consent to participate: This study was conducted with the ethical approval of Fujian Medical University Institutional Animal Care Committee and the Fujian Provincial Hospital Animal Care and Use Committee. All animals received treatments in compliance with the National Research Council's 1996 Guide for the Care and Use of Laboratory Animals.

Consent for publication: Not applicable.

Availability of data and materials: Not applicable.

Competing interests: The authors declare that they have no competing interests.

Funding: This study was supported by Medical Education Branch of the Chinese Medical Association, Medical Education Committee of the Chinese Higher Education Society (2016B-LC033), Natural science foundation of Fujian province (2018J01246), and Medical innovation project of Fujian province (2018$\mathrm{CX}-2$ ). They provided funding for this research and did not influence the design of the study, data collection and analysis, interpretation of data and the writing of the manuscript.

Authors' contributions: FH carried out the studies and drafted the manuscript. FC participated in the design of the study and helped to carry out the studies. XZ conceived the study, participated in its design and coordination, and helped to draft the manuscript. FG was responsible for data collection and performed the statistical analysis. All authors read and approved the final manuscript.

Acknowledgements: Not applicable.

\section{References}

1.Vasdev GM, Harrison BA, Keegan MT, Burkle CM. Management of the difficult and failed airway in obstetric anesthesia. Journal of Anesthesia. 2008;22(1):38-48.

2.Caplan RA, Benumof JL, Berry FA, Blitt CD, Bode RH, Cheney FW, et al. Practice guidelines for management of the difficult airway. Anesthesiology. 2003;98(1269-1277):2.

3.Elorbany M, Woehlck HJ. Difficult mask ventilation. Anesthesia \& Analgesia. 2009;109(6):1870-80.

4.Yong-chun L. General Injection Anesthesia in Dogs and Cats. Progress in Veterinary Medicine. 2009.

5.Wang Z, Xie P, Lu CR, Wang H. Effect of compound anesthesia by Sumianxin with ketamine on respiration and circulation system of dogs. Chinese Journal of Veterinary Science. 2009;29(12):1610-2.

6.Schoch HJ, Fischer S, Marti HH. Hypoxia-induced vascular endothelial growth factor expression causes vascular leakage in the brain. Brain. 2002;125(11):2549-57.

7.Peterson GN, Domino KB, Caplan RA, Posner KL, Lee LA, Cheney FW. Management of the difficult airway: a closed claims analysis. Anesthesiology. 2005;103(1):33-9. 
8.Wong DT, Lai K, Chung FF, Ho RY. Cannot intubate-cannot ventilate and difficult intubation strategies: results of a Canadian national survey. Anesth Analg. 2005;100(5):1439-46, table of contents.

9.Hsia CC, Hyde DM, Weibel ER. Lung Structure and the Intrinsic Challenges of Gas Exchange. Compr Physiol. 2016;6(2):827-95.

10.Shirasaki Y, Edo N, Sato T. Serum S-100b protein as a biomarker for the assessment of neuroprotectants. Brain Res. 2004;1021(2):159-66.

11.Sheng-He H, Lin W, Feng C, Chun-Hua W, Hong C, Aimin Z, et al. Circulating brain microvascular endothelial cells (CBMECs) as potential biomarkers of the blood-brain barrier disorders caused by microbial and non-microbial factors. Plos One. 2013;8(4):e62164.

12.Marchi N, Cavaglia M, Fazio V, Bhudia S, Hallene K, Janigro D. Peripheral markers of blood-brain barrier damage. Clin Chim Acta. 2004;342(1-2):1-12.

13.Chaparro-Huerta V, Flores-Soto ME, Merin Sigala ME, Barrera de Leon JC, Lemus-Varela ML, TorresMendoza BM, et al. Proinflammatory Cytokines, Enolase and S-100 as Early Biochemical Indicators of Hypoxic-Ischemic Encephalopathy Following Perinatal Asphyxia in Newborns. Pediatr Neonatol. 2017;58(1):70-6.

14.Sarada SK, Titto M, Himadri P, Saumya S, Vijayalakshmi V. Curcumin prophylaxis mitigates the incidence of hypobaric hypoxia-induced altered ion channels expression and impaired tight junction proteins integrity in rat brain. J Neuroinflammation. 2015;12:113.

15.Beaumont A, Marmarou A, Fatouros P, Corwin F. Secondary Insults Worsen Blood Brain Barrier Dysfunction Assessed by MRI in Cerebral Contusion. Acta Neurochir Suppl. 2002;81:217-9.

16.Bodor GS, Porterfield D, Voss EM, Smith S, Apple FS. Cardiac troponin-I is not expressed in fetal and healthy or diseased adult human skeletal muscle tissue. Clinical Chemistry. 1995;41(12):1710-5.

17. Maynard S, Menown I, Adgey A. Troponin T or troponin I as cardiac markers in ischaemic heart disease. BMJ Publishing Group Ltd and British Cardiovascular Society; 2000.

18.Rajappa M, Sharma A. Biomarkers of cardiac injury: an update. Angiology. 2005;56(6):677-91.

\section{Figures}



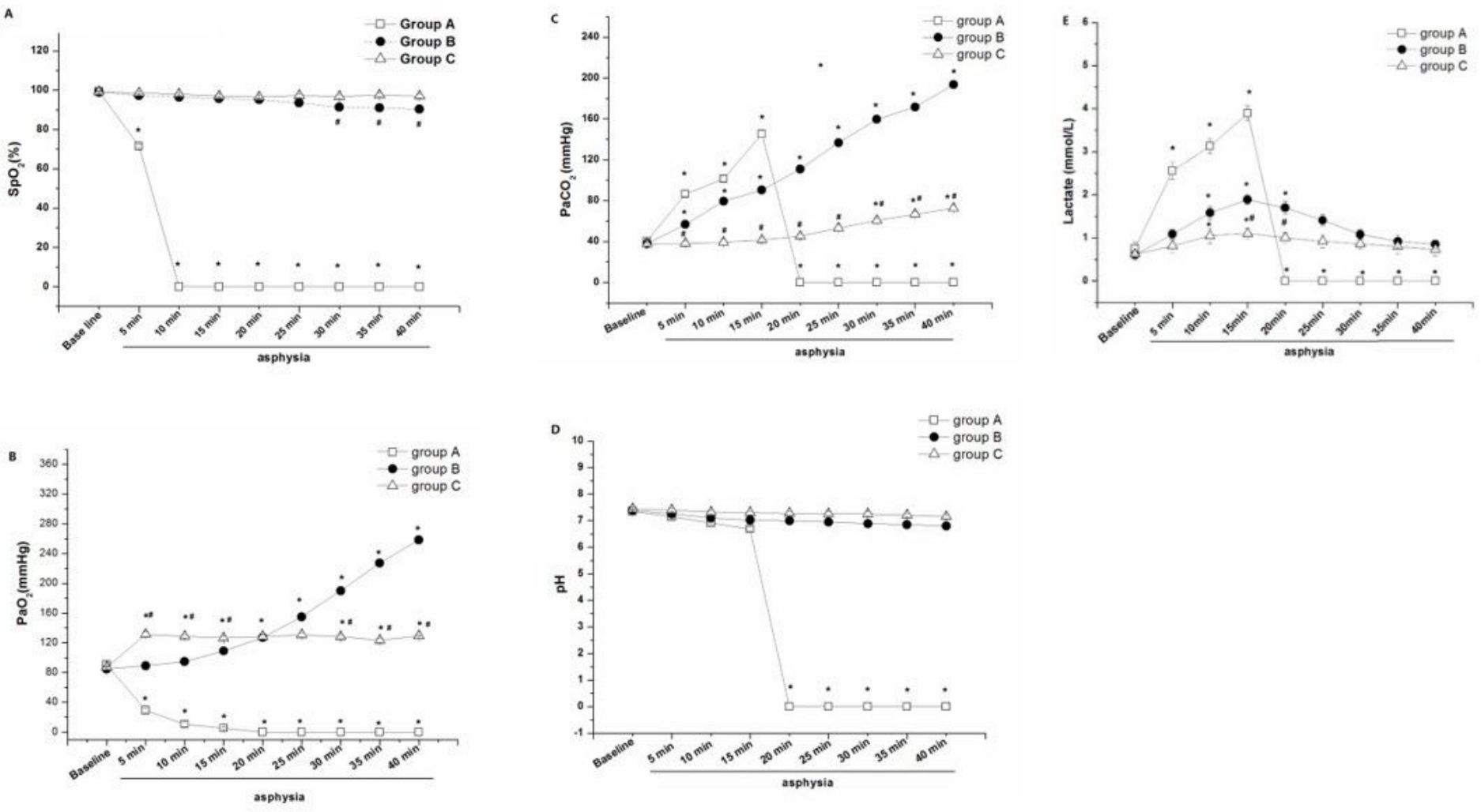

\section{Figure 1}

Comparison of arterial blood gas analysis parameters among group $\mathrm{A}, \mathrm{B}$ and $\mathrm{C}$. The measurements were made at baseline and at varying time points up to 40 minutes post-hypoxia. A. SpO2; $\mathrm{B}$. $\mathrm{PaO} 2$; C. $\mathrm{PaCO}$; D. $\mathrm{pH} ; \mathrm{E}$. Lactate. The values are presented as mean $\pm \mathrm{SD}$. ${ }^{\star} \mathrm{p} \otimes 0.05 \mathrm{vs}$. baseline; $\# \mathrm{p} \otimes 0.05$ vs. group $B$. 

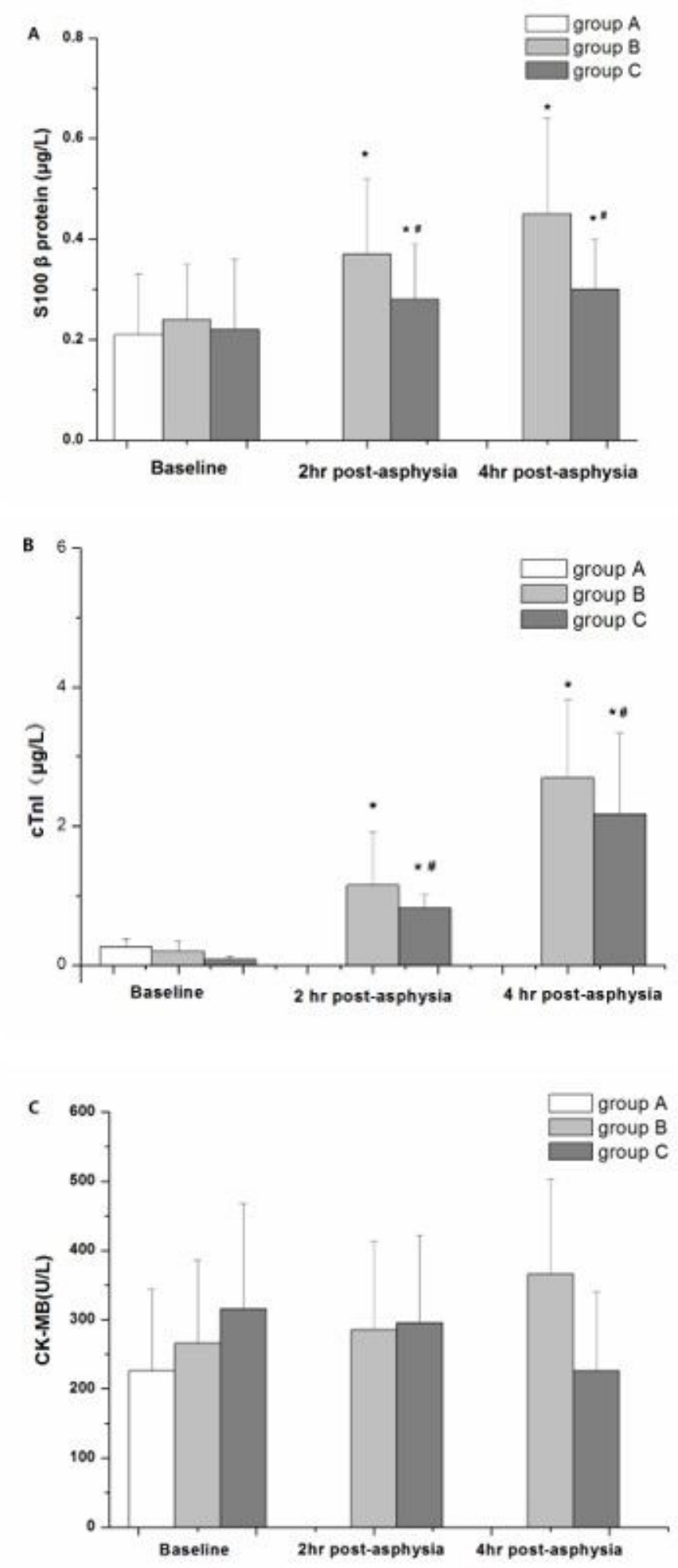

\section{Figure 2}

Comparison of serum $\mathrm{S} 100 \beta$ protein, $\mathrm{CTnl}$, and CK-MB among group A, B and C. The measurements were made at baseline and at varying time points of 2 and 4 hours post-hypoxia. A. S100 $\beta$ protein; B. cTnl; C. CK-MB. The values are presented as mean \pm SD. ${ }^{*} \mathrm{p} \otimes 0.05$ vs. baseline; $\# \mathrm{p} \otimes 0.05$ vs. group $B$. 


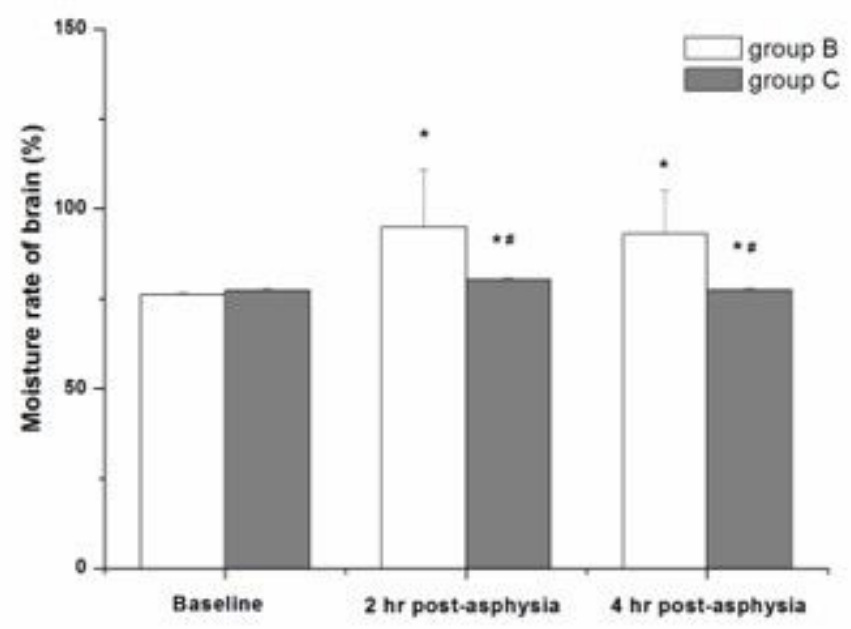

Figure 3

Comparison of moisture ratio of brain tissue among group A, B and C. The measurements were made at baseline and at varying time points of 2 and 4 hours post-hypoxia. The values are presented as mean \pm SD. ${ }^{*} \mathrm{p} \otimes 0.05$ vs. baseline; $\# \mathrm{p} \otimes 0.05$ vs. group $B$. 

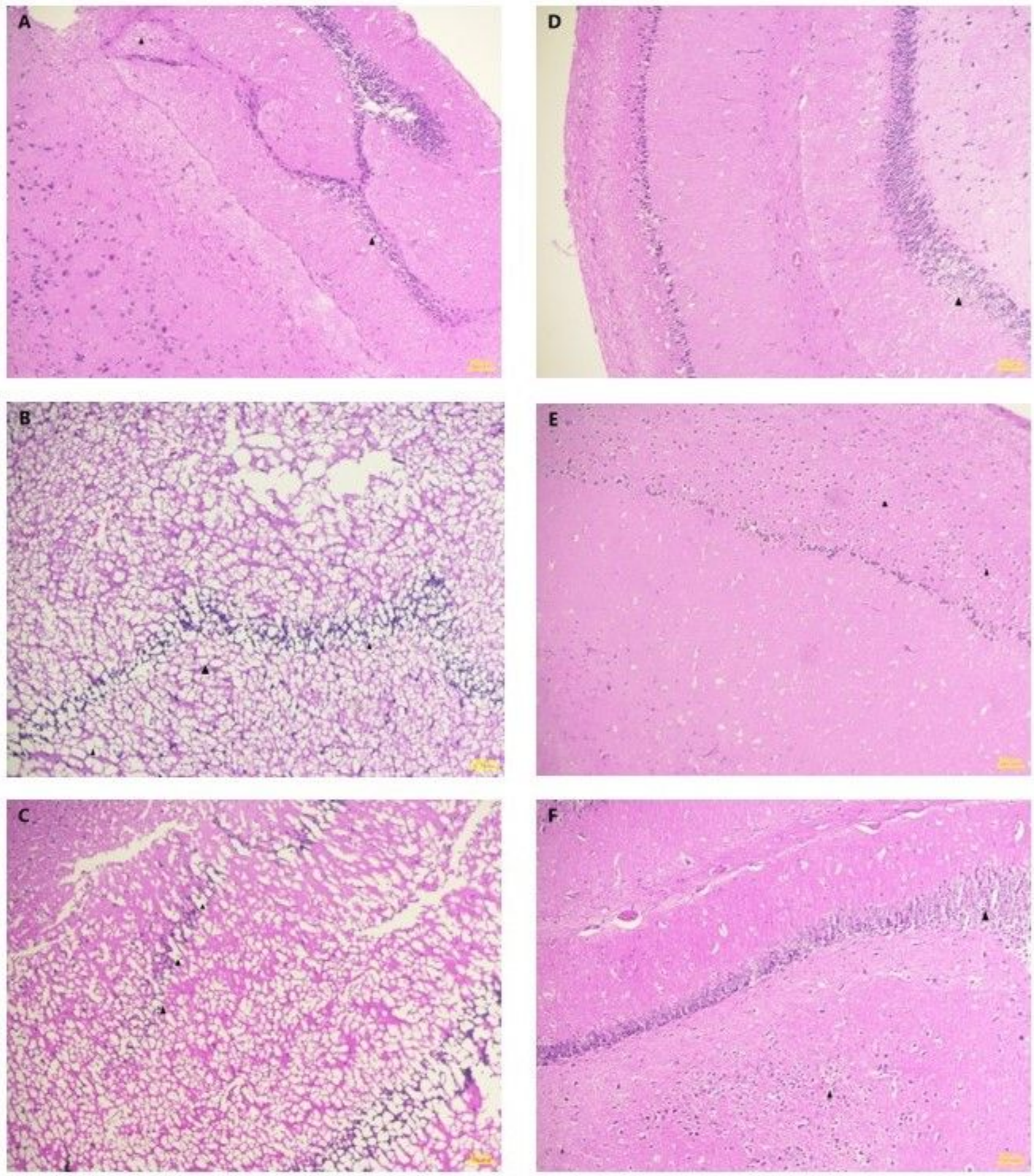

\section{Figure 4}

The histology of brain edema in group B and group C. group B: Under the microscope $\$ The brain parenchyma did not show hemorrhage and vacuoles of different sizes can be seen. The tissue is loosely arranged and the neurons and perivascular spaces are enlarged. The neurons are degenerated and necrotic, and neutrophils and microglia can be seen. (black arrows $\bigotimes$ fig 4A囚Baseline, fig 4B囚2 hours postasphyxia, fig 4C $\varangle 4$ hours post-asphyxia) group C: Under the microscope邓The brain parenchyma did now 
show hemorrhage and a small number of vacuoles of different sizes can be seen. The tissue is tightly arranged and the neurons and perivascular spaces are enlarged. The neurons are degenerated and slightly necrotic, and a few neutrophils and microglia can be seen. (black arrows $\varangle$ fig 4D囚Baseline, fig 4E 2 hours post-asphyxia, fig $4 \mathrm{~F} \otimes 4$ hours post-asphyxia)

\section{Supplementary Files}

This is a list of supplementary files associated with this preprint. Click to download.

- NC3RsARRIVEGuidelinesChecklist.docx

- eq1.jpg 